\title{
A QUANTITATIVE ANALYSIS OF SPIRITUALITY AND SOCIAL SUPPORT WITH ITS IMPACT ON CANCER PATIENTS' QUALITY OF LIFE
}

\author{
Abid Ali ${ }^{\boxplus}$, Niaz Muhammad', Ihsan Ullah Khan ${ }^{2}$
}

\section{ABSTRACT}

OBJECTIVE:To investigate the level of spirituality and social support along with its impact on health related quality of life (QoL) in cancer patients.

METHODS: This cross-sectional study was conducted from I5th July to 3 Ist August 2018 on 200 patients selected through purposive sampling. Pre-validated questionnaires were used to collect the data on spirituality, social support and QoL, which were analyzed using SPSS v.20.0. Descriptive and inferential statistics were applied where needed.

RESULTS: In 200 patients, I5 I (75.5\%) were male, majority ( $n=70 ; 35 \%)$ were from $>48$ to 58 years of age group, maximum $(n=116 ; 58 \%)$ were unmarried, while majority had primary education $(n=62 ; 31 \%)$. Laryngeal carcinoma $(n=24$; $12 \%)$, was the commonest clinical presentation followed by breast cancer $(n=23$; I I.5\%). Majority $(n=77 ; 38.5 \%)$ presented at Stage III, I $40(70 \%)$ reported it to be diagnosed at first evaluation, 161 ( $80.5 \%)$ had no family history, $109(54.5 \%)$ reported to start spiritual treatment after diagnosis, and 1 I 7 (58.5\%) reported family as their main support during the whole phase. In spirituality distinctiveness, $68(34 \%)$ patients showed very high spiritual level, 72 (36\%) reported to recite specific Quranic verses in religious practice, in which 1 I 2 (56\%) reported to

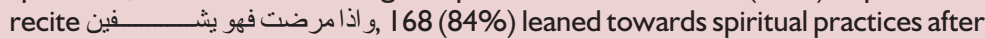
diagnosis. In correlation, spirituality $(2.42 \pm 0.596)$ and social support (2.19 \pm 0.568$)$, both had a significant correlation with QoL $(2.37 \pm 0.494)$ with values of $r=0.289, p=0.000$ and $r=0.238, p=0.001$ respectively.

CONCLUSION: Spirituality and social support are the key coping mechanisms that have supportive influences on the patients' overall health-related QoL.

KEY WORDS: Spirituality (MeSH); Quality of Life (MeSH); Cancer (MeSH); Social Support $(\mathrm{MeSH})$.

THIS ARTICLE MAY BE CITED AS: Ali A, Muhammad N, Khan IU. A quantitative analysis of spirituality and social support with its impact on cancer patients' quality of life. Khyber Med Univ J 2020;|2(2):|26-3|. DOI: $10.35845 / \mathrm{kmuj} .2020 .19939$.

\section{INTRODUCTION}

$\longrightarrow$ ancer is a major health burden globally and recent statistics shows that 18.1 million fresh cases are diagnosed and 9.6 million deaths are reported, worldwide in $2018 . '$ In Pakistan, the ratio of cancer is rising and a total of 173937 new cases have been reported by GLOBOCAN in 20 I 8. ${ }^{2}$ This may be due to various reasons such as no annual or appropriate medical checkup, expensive medical treatment, fear of disease, prevalent pessimistic public opinions and several common myths regarding the disease. Moreover, proper medical facilities are also not accessible to all, as it is believed to be an incurable disease, so mostly dealt with various traditional and allied healthcare approaches. $^{3}$ People frequently attain health recovery by performing certain supportive medical and spiritual practices for various diseases. Spirituality is one of those particular coping mechanisms and currently gaining more importance in the academic and clinical research fields. ${ }^{5}$ It has been defined as a set of internal feelings through which an individual search for meaning and purpose of life
I. Department of Sociology, University of Peshawar, Peshawar, Pakistan

2. Department of Sociology, FATA University,TSD Dara Adam Khel, Kohat, Pakistan

Email凶: abidalisocio472@ gmail.com Contact \# : +92-345-9354472

Date Submitted:

December II, 2019

Date Revised:

March 13, 2020

Date Accepted:

March 20, 2020

and associates it with self, intimates, nature and sacred. ${ }^{6}$

Several research studies acknowledged the role of spirituality among cancer patients and noted that spirituality has been practiced ${ }^{7}$ and it was found helpful in repercussions on the enhancement of patients' quality of life (QoL), ${ }^{8}$ their functional wellbeing, ${ }^{9}$ physical wellbeing ${ }^{10}$ and decrease stress symptoms among cancer patients." Furthermore, another study reported that prayers, reading of the holy scripts and meditation can also improve sense of control over stress and ultimately enhances patients' QoL. ${ }^{12}$

Besides, social support also plays an essential role in the cancer patients QoL ${ }^{13}$ and higher levels of social support was associated with lesser death rates, ${ }^{14}$ better post-traumatic progression, ${ }^{15}$ greater levels of physical activity, ${ }^{16}$ better overall health ${ }^{17}$ and lower level of stress. ${ }^{18}$ Some researchers have pointed out that if a greater level of social support is delivered under stress situations, a high decrease can be observed in emotional and functional symptoms. ${ }^{19}$ Another study reported that social support decreases the psychological troubles and hopelessness while increasing cancer patients' QoL. ${ }^{20}$ Keeping in view the salutary role of spirituality and social support, this study was planned to find out its impact on patients' QoL. However, a great research work done in western religions/cultures but no such kinds of research or survey has been conducted in Pakistan, although such practices are dominant in our society. This may be due to the pre-eminence of bio-medical treatment mechanisms which neglected the influence of theses coping strategies. Therefore, it was 
TABLE I: DEMOGRAPHIC PROFILE OF THE STUDY PARTICIPANTS

\begin{tabular}{|l|l|c|c|}
\hline \multicolumn{2}{|c|}{ Variable } & Frequency $(\mathbf{n = 2 0 0})$ & Percentage \\
\hline \multirow{4}{*}{ Gender } & Male & I5I & 75.5 \\
\cline { 2 - 4 } & Female & 49 & 24.5 \\
\hline \multirow{4}{*}{ Age Group } & $18-28$ & 35 & 17.5 \\
\cline { 2 - 4 } & $>28-38$ & 34 & 17.0 \\
\cline { 2 - 4 } & $>38-48$ & 44 & 22.0 \\
\cline { 2 - 4 } & $>48-58$ & 70 & 35.0 \\
\cline { 2 - 4 } & $>58-68$ & 12 & 6.0 \\
\cline { 2 - 4 } & $>68$ & 5 & 2.5 \\
\hline \multirow{5}{*}{ Marital Status } & Widower/widow & 20 & 10.0 \\
\cline { 2 - 4 } & Unmarried & 116 & 58.0 \\
\cline { 2 - 4 } & Married & 63 & 31.5 \\
\cline { 2 - 4 } & Divorced & 1 & 0.5 \\
\hline \multirow{5}{*}{ Educational Level } & Illiterate & 25 & 12.5 \\
\cline { 2 - 4 } & Primary & 62 & 31 \\
\cline { 2 - 4 } & High School & 57 & 28.5 \\
\cline { 2 - 4 } & HSS & 20 & 17.5 \\
\cline { 2 - 4 } & Bachelor & 1 & 0.5 \\
\cline { 2 - 4 } & Master & & \\
\hline
\end{tabular}

TABLE II: CLINICAL PROFILE OF THE STUDY PARTICIPANTS

\begin{tabular}{|c|c|c|c|}
\hline \multicolumn{2}{|c|}{ Variable } & \multirow{2}{*}{$\begin{array}{c}\begin{array}{c}\text { Frequency } \\
(\mathrm{n}=200)\end{array} \\
16\end{array}$} & \multirow{2}{*}{\begin{tabular}{|c|} 
Percentage \\
8.0 \\
\end{tabular}} \\
\hline \multirow{13}{*}{ Type of Cancer } & Colon & & \\
\hline & Breast & 23 & $1 \mathrm{I} .5$ \\
\hline & Prostate & 12 & 6.0 \\
\hline & Lung & 18 & 9.0 \\
\hline & Laryngeal & 24 & 12.0 \\
\hline & Lymphoma & 13 & 6.5 \\
\hline & Myeloid & 11 & 5.5 \\
\hline & Liver & 17 & 8.5 \\
\hline & Gastric & 15 & 7.5 \\
\hline & Bladder & 15 & 7.5 \\
\hline & Leukemia & 11 & 5.5 \\
\hline & Renal & 10 & 5.0 \\
\hline & Brain/Cantal nervous system & 15 & 7.5 \\
\hline \multirow{4}{*}{ Cancer Stage } & Stage I & 29 & 14.5 \\
\hline & Stage 2 & 52 & 26.0 \\
\hline & Stage 3 & 77 & 38.5 \\
\hline & Stage 4 & 42 & 21.0 \\
\hline \multirow{2}{*}{ First Time Diagnosed } & Yes & 140 & 70.0 \\
\hline & No & 60 & 30.0 \\
\hline \multirow{3}{*}{ Family History of Cancer } & Yes & 29 & 14.5 \\
\hline & No & 161 & 80.5 \\
\hline & Don't know & 10 & 5.0 \\
\hline \multirow{3}{*}{$\begin{array}{l}\text { Kind of Treatment } \\
\text { Consulted at the first Time }\end{array}$} & Spiritual & 109 & 54.5 \\
\hline & Medical & 38 & 19 \\
\hline & Both together & 53 & 26.5 \\
\hline \multirow{4}{*}{$\begin{array}{l}\text { Received Social Support } \\
\text { from }\end{array}$} & Spouse/partner & 55 & 27.5 \\
\hline & Family & 117 & 58.5 \\
\hline & Friends & 18 & 9 \\
\hline & Healthcare professionals & 10 & 5 \\
\hline
\end{tabular}

crucial to conduct a research survey specifically on Muslim spiritual and social support practices along with its impact on health related QoL in cancer patients.

\section{METHODS}

This cross-sectional survey was approved by the Advanced Studies and Research Board (ASRB), University of Peshawar and was conducted from I5th July to 3I August 20 I 8 at the Institute of Radiotherapy and Nuclear Medicine (IRNUM) hospital, Peshawar. A structured questionnaire was used for quantitative data and collected through a purposive sampling technique. A sample size of 200 respondents out of 415 patients was selected for data collection purpose according to Sekaran $^{21}$ sample size. An individual diagnosed as a cancer patient, age of 18 years or above and Muslims were included while those with any mental/psychological were excluded from this study. Firstly, the questionnaire was developed in the English language and translated into Urdu for the understanding of the enrolled respondents in order to achieve the required information. Illiterate patients were interviewed for the research tool while among rest the tool was self-administered. For measuring the patients', levels of spirituality, the Peterman et al. ${ }^{22}$ I2items scale (Functional Assessment of Chronic Illness Therapy-Spiritual wellbeing scale (FACIT-Sp) was adopted. Likewise, the Berlin Social Support Scale (BSSS) was used to measure the social support aspects. ${ }^{23}$ For QoL, the Functional Assessment of Cancer Therapy (FACT) scale was used. ${ }^{24}$ All the responses were measured by a five-point Likert scale ranging from $0=$ not at all to $4=$ very much and same was interpreted as per interpretation available in literature. ${ }^{22-24}$

After data collection, extraction was made which was then examined through SPSS V.20. Descriptive statistics were applied for categorical and numerical variable. In bi-variate analysis, all the selected variables were indexed properly and then evaluated by Pearson's Correlation Coefficient test. Spirituality and social support were 
TABLE III: SPIRITUAL DISTINCTIVENESS OF THE RESPONDENTS

\begin{tabular}{|c|c|c|c|}
\hline & Variable & $\begin{array}{c}\text { Frequency } \\
(n=200)\end{array}$ & Percentage \\
\hline \multirow{4}{*}{ Spirituality level } & Low & 14 & 7.0 \\
\hline & Medium & 45 & 22.5 \\
\hline & High & 73 & 36.5 \\
\hline & Very High & 68 & 34.0 \\
\hline \multirow{10}{*}{$\begin{array}{l}\text { Spiritual / Religious } \\
\text { Practices }\end{array}$} & Petitionary prayer & 21 & 10.5 \\
\hline & Pray & 8 & 4.0 \\
\hline & Recitation of holy scripts & 33 & 16.5 \\
\hline & Rosary & 14 & 7.0 \\
\hline & Spells & 12 & 6.0 \\
\hline & Amulet & 13 & 6.5 \\
\hline & Visit a Spiritual Healer & 10 & 5.0 \\
\hline & Specific Quranic Verses & 72 & 36.0 \\
\hline & Fasting & 13 & 6.5 \\
\hline & Holy water/ Zam Zam water & 4 & 2.0 \\
\hline \multirow{4}{*}{$\begin{array}{l}\text { Specific Quranic verses } \\
\text { practiced }\end{array}$} & Surah Ar-Rahman & 14 & 7 \\
\hline & $\begin{array}{l}\text { The } 4 \text { Quls (Surah Al-Kafiroun, } \\
\text { Al-Ikhlas, Al-Falaq, An-Nas) }\end{array}$ & 36 & 18 \\
\hline & إزامر ضت فهو يشفين (1) وارئ & 112 & 56 \\
\hline & وننزل من القر آن ماهوشفاء (2) & 38 & 19 \\
\hline \multirow{3}{*}{$\begin{array}{l}\text { Tend towards } \\
\text { spiritual practices }\end{array}$} & Before diagnosis & 20 & 10 \\
\hline & After diagnosis & 168 & 84 \\
\hline & Never changed and as usual & 12 & 6 \\
\hline
\end{tabular}

1. And when I am ill, it is He Who cures $m e ; 2$. What We have sent down of the Qur'an is a healing

TABLE IV: MEAN AND STANDARD DEVIATION OF THE VARIABLES

\begin{tabular}{|l|l|l|}
\hline \multicolumn{2}{|c|}{ Variable } & Mean \pm S.D \\
\hline \multirow{5}{*}{ Spirituality } & Meaning & $2.55 \pm 0.825$ \\
\cline { 2 - 3 } & Peace & $2.65 \pm 0.813$ \\
\cline { 2 - 3 } & Faith & $2.45 \pm 0.86 \mathrm{I}$ \\
\cline { 2 - 3 } & Spirituality & $2.42 \pm 0.596$ \\
\hline \multirow{5}{*}{ Social Support } & Emotional Support & $2.45 \pm 0.855$ \\
\cline { 2 - 3 } & Instrumental Support & $2.31 \pm 0.888$ \\
\cline { 2 - 3 } & Informational Support & $2.42 \pm 1.024$ \\
\cline { 2 - 3 } & Need for Support & $2.37 \pm 0.778$ \\
\cline { 2 - 3 } & Support Seeking & $2.08 \pm 0.850$ \\
\cline { 2 - 3 } & Social Support & $2.19 \pm 0.568$ \\
\hline & Physical Wellbeing & $2.38 \pm 0.747$ \\
\cline { 2 - 3 } & Social Wellbeing & $2.44 \pm 0.655$ \\
\cline { 2 - 3 } & Emotional Wellbeing & $2.67 \pm 0.703$ \\
\cline { 2 - 3 } & Functional Wellbeing & $2.39 \pm 0.721$ \\
\cline { 2 - 3 } & Quality of Life & \\
\hline
\end{tabular}

taken as independent and QoL as a dependent variable.

\section{RESULTS}

In 200 respondents as per gender classification, majority of the patients were males $(n=|5|, 75 \%)$ while in age group, majority of respondents were cancer. In stages of carcinoma, majority of the patients had Stage-III cancer $(n=77,38.5 \%)$ and $(n=29,14.5 \%)$ patients had Stage-I cancer patients rest details can be seen table: II. In spiritual specifications majority of the patients were highly spiritual $(n=73,36.5 \%)$ and $(n=68,34 \%)$ were very high spiritual patients. Additionally, patients practiced various categories of spiritual practices for healing purposes and majority of the respondents practiced the recitation of specific Quranic verses ( $n=72,36 \%)$ and only $(n=4,2 \%)$ used Zam Zam water (Holy water) for healing purposes, details given in table: III. Table IV of the result section shows mean $\pm S D$ calculated for different variables of the study.

In the end, correlation analysis (direction/strength of the relationship denoted by $(r)$ and significance by $(p)$ of the selected variables) was conducted. After indexation of variables, correlation was calculated. The outcomes showed that the association was insignificant between overall spirituality and with both physical wellbeing $(p=.742)$ and social wellbeing $(p=.994)$ aspects of the QoL. Whereas, spirituality has a positive and significant relationship with both emotional wellbeing $(p=.00 \mathrm{l})$ and functional wellbeing $(p=.000)$. The details are based on Table $\mathrm{V}$.

\section{DISCUSSION}

The present research survey focused on investigating the impacts of spirituality and social support on cancer patients' health-related QoL. The outcomes showed that cancer patients have high level of belief in spirituality/spiritual practices (70\%). The parallel results also recorded by Burt, ${ }^{25}$ that patients with cancer have high spiritual level and rely on spiritual healing practices due to the chronic condition of illness. Also, (36\%) patients practice the recitation of the Holy Quranic verses and (10\%) perform prayers for cure. It further reveals that majority of the patients become spiritual after the disease diagnosed (84\%) and they consider it a source of strength, healing and have positive impacts on a patient's wellbeing. The present study has also similar results with that of McSherry ${ }^{26}$ 
3. Byrne SK. Healthcare avoidance: a critical review. Holist Nurs Pract 2008;22(5):280-92. DOI: 10.1097/ 0I.HNP.000033492I.3I433.c6.

4. Tuck I, Wallace D, Pullen L. Spirituality and spiritual care provided by parish nurses. West J Nurs Res 200I;23(5):44I-53. DOI: I0.1I77/0|939450| 22045294 .

5. Stefanek M, McDonald PG, Hess SA. Religion, spirituality and cancer: current status and methodological challenges. Psychooncology 2005; I4(6):450-63. DOI: 10.1002 /pon.86I.

6. Tuck I. Development of a spirituality intervention to promote healing. J Theory Const Test 2004;8(2):67-70

7. de Jager Meezenbroek E, Garssen B, van den Berg $M$, van Dierendonck D, Visser A, Schaufeli WB, et al. Measuring spirituality as a universal human experience: a review of spirituality questionnaires. J Relig Health 20I2;5I(2):336-54. DOI: 10.1007/s 10943-010-9376-I.

8. Lim JW, YiJ. The effects of religiosity, spirituality, and social support on quality of life: a comparison between Korean American and Korean breast and gynecologic cancer survivors. Oncol Nurs Forum 2009;36(6):699-708. DOI: 10.1188/09.ONF.699-708.

9. Shahmoradi N, Kandiah M, Loh SP. Quality of life and functional status in patients with advanced cancer admitted to hospice home care in Malaysia: a cross-sectional study. $\mathrm{EurJC}$ a n c e r C a r e 20I 2;2I(5):66 I-66. DOI: I0.III I lj. 1365-2354.20I2.01338.x.

10. Kim Y, Seidlitz L. Spirituality moderates the effect of stress on emotional and physical adjustment. J Individ Differ 2002 Jun I; 32 (8): I377-90. DOI: $10.1016 / \mathrm{SO} 191$ 8869(0I)00I28-3.

I I. Rawdin B, Evans C, Rabow MW. The relationships among hope, pain, psychological distress, and spiritual well-being in oncology outpatients. J Palliat Med 2013;16(2):167-72. DOI: I0.1089/jpm.20I 2.0223 .

12. Thuné-Boyle IC, Stygall J, Keshtgar
MR, Davidson TI, Newman SP Religious/spiritual coping resources and their relationship with adjustment in patients newly diagnosed with breast cancer in the U K. Ps y chooncolog y 20I3;22(3):646-58. DOI: 10.1002 /pon.3048.

13. Smith AR, DeSanto-Madeya S, Pérez JE, Tracey EF, DeCristofaro S, Norris RL, et al. How women with advanced cancer pray: a report from two focus groups. Oncol Nurs Forum 20I2;39(3):E3।0-6. DOI:I0.| |88/|2.ONF.E3 |0-E3|6.

14. Kroenke K, Johns SA, Theobald D, Wu J, Tu W. Somatic symptoms in cancer patients' trajectory over 12 months and impact on functional status and disability. Support Care Cancer 20I3;2I(3):765-73. DOI: 10.1007/s00520-0| 2-I578-5.

15. Schroevers MJ, Helgeson VS, Sanderman R, Ranchor AV. Type of social support matters for prediction of posttraumatic growth among cancer survivors. Psychooncology 2010;19(I):46-53. DOI: I0.1002/pon.I50I.

16. Barber FD. Social support and physical activity engagement by cancer survivors. Clin J Oncol Nurs 20I2; I6(3): :E84-98. DOI: 10.1188 / I2.CJON.E84-E98.

17. Ganz PA, Greendale GA, Petersen L, Kahn B, Bower JE. Breast cancer in younger women: reproductive and late health effects of treatment. J Clin Oncol 2003;2I(22):4I84-93. DOI: I0.1200/JCO.2003.04.196.

18. Andreu Y, Galdón MJ, Durá E, Martínez P, Pérez S, Murgui S. A longitudinal study of psychosocial distress in breast cancer: prevalence and risk factors. Psychol Health 20I2;27(I):72-87. DOI: 10.1080 /08870446.20I0.5428I4.

19. Hill J, Holcombe C, Clark L, Boothby MR, Hincks A, Fisher J, et al. Predictors of onset of depression and anxiety in the year after diagnosis of breast cancer. Psychol Med 20I I;4I (7): I429-36. DOI: 10. I017/S0033291710001868.

20. Thompson T, Rodebaugh TL, Pérez
M, Schootman M, Jeffe DB. Perceived social support change in patients with early stage breast cancer and controls. Health Psychol 2013;32(8):886-95. DOI: 10.1037 /a003/894.

2I. Sekaran U. Research methods for business: A skill building approach. John Wiley; 2003. [Accessed on: November II, 2019]. Available from URL: https://iaear. weebly .com/uploads/2/6/2/5/26257I06/re search_methods_entiree_book_u masekaram-pdf- I 30527। 24352phpapp02.pdf.

22. Peterman AH, Fitchett G, Brady MJ, Pharm D, Cella D. The Functional Assessment of Chronic Illness Therapy-Spiritual Well-Being Scale (FACIT-Sp). Ann Behav Med. 2002;24(I):49-58. DOI: 10.1207 /SI5324796ABM240I_06.

23. Schwarzer R, Schulz U. Berlin Social Support Scales (BSSS). Measurement Instrument Database for the Social Science. 2013. [Accessed on: November II, 2019] Available from URL: https:// www.midss.org/sites/default/files/b sss_brief_documentation.pdf.

24. Cella DF. Quality of life: Concepts and definitions. J Pain Symptom Manage 1994 Apr;9(3):186-92. DOI: 10.1016/0885-3924(94) 901 29-5.

25. Burt N. Hope and spirituality and their relationship to the overall quality of life in cancer patients. [Doctoral Dissertation] Department of Communication Disorders and Counseling, School, and Educational Psychology, Indiana State University, Terre Haute, Indiana. 2010

26. McSherry W. Making sense of spirituality in nursing practice: An interactive approach. WB Saunders Company; 2000. [Accessed on: November 14, 2019]. Available from URL: https://www.hpb.com /products/making-sense-ofspirituality-in-nursing-practice9780443063565

27. Kim HS, Sherman DK, Taylor SE. Culture and social support. Am Psychol 2008;63(6):5I8-26. DOI: 
10.1037/0003-066X.

28. Melo Filho MR, Rocha BA, Pires MB, Fonseca ES, Freitas EM, et al. Quality of life of patients with head and neck cancer. BrazJ Otorhinolaryngol 2013;79(I):82-8. DOI: $10.5935 / 1808-8694$ .20130014 .

29.Jassim GA, Whitford DL. Understanding the experiences and quality of life issues of Bahraini women with breast cancer. Soc Sci Med 20|4;107:189-95. DOI: I0.1016/j.socscimed.2014.01.03।.

30. Sawatzky R, Ratner PA, Chiu L. A meta-analysis of the relationship between spirituality and quality of life. J Soc Indic Res 2007;72(2): I5388. DOI: $|0| .007 / \mathrm{s}|| 205-004-5$ 577-x

31. Samsi M. A cognitive model of spiritual beliefs and breast cancer recurrence fears: implications for psychological functioning. Dissertation, University of Houston. 2008. [Accessed on: November 19, 2019]. Available from URL: https:// uh ir.tdl.org/bitstream/handle/ I0657/9 I 7/ANDERSON-DISSERTATION20I 2 .pdf?sequence $=\mid$ \& \&isAllowed $=\mathrm{y}$.

32) Koenig HG. Religion, spirituality, and health: the research and clinical implications. ISRN Psychiatry 20।2;20|2:278730. DOI: $10.5402 / 2012 / 278730$.

33) Yamagishi A, Sato K, Miyashita $M$, Shima Y, Kizawa $Y$, Umeda $M$, et al. Changes in quality of care and quality of life of outpatients with advanced cancer after a regional palliative care intervention program. J Pain Symptom Manage 20।4;48(4):602-I0. DOI:
10.1016/j.jpainsymman.2013.1I.0I 6.

34. Lim JW, Zebrack B. Different pathways in social support and quality of life between Korean American and Korean breast and gynecological cancer survivors. Qual Life Res 2008;17(5):679-89. DOI: |0.1007/s | | |36-008-9343-4.

35. Filazoglu G, Griva K. Coping and social support and health-related quality of life in women with breast cancer in Turkey. Psychol Health Med 2008; I3(5):559-73. DOI: 10. I080/I354850070I 767353 .

36. Epplein M, Zheng Y, Zheng W, Chen Z, Gu K, Penson D, et al. Quality of life after breast cancer diagnosis and survival. J Clin Oncol 20II;29(4):406-I2. DOI: 10.1200 /JCO.20I0.30.695I.

\section{AUTHORS' CONTRIBUTIONS}

Following authors have made substantial contributions to the manuscript as under:

AA: Conception and study design, acquisition of data, drafting the manuscript, final approval of the version to be published.

NM: Study design, critical review, final approval of the version to be published.

IUK: Analysis and interpretation of data, drafting the manuscript, final approval of the version to be published

Authors agree to be accountable for all aspects of the work in ensuring that questions related to the accuracy or integrity of any part of the work are appropriately investigated and resolved.

\begin{tabular}{|c|}
\hline CONFLICT OF INTEREST \\
Authors declared no conflict of interest \\
GRANT SUPPORT AND FINANCIAL DISCLOSURE \\
NIL
\end{tabular}

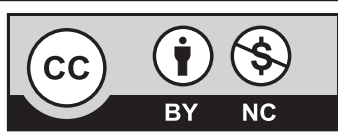

This is an Open Access article distributed under the terms of the Creative Commons Attribution-Non Commercial 2.0 Generic License.

KMUJ web address: www.kmuj.kmu.edu.pk Email address: kmuj@kmu.edu.pk 